\title{
Research on Administrative Accountability System under the Perspective of Responsible Government
}

\author{
Wenjie Yi \\ School of Literature, law and Economics \\ Wuhan University of Science and Technology \\ Wuhan, Hubei, China 430065
}

\author{
$\operatorname{Min} \mathrm{Li}^{*}$ \\ School of Literature, law and Economics \\ Wuhan University of Science and Technology \\ Wuhan, Hubei, China 430065 \\ *Corresponding author
}

\begin{abstract}
Since the 1980 s, various countries in the world tend to build responsible government through their administrative reforms. The report of the 18th CPC National Congress has proposed clear goals for government administration system reform under new historical conditions, namely to establish a law-based government and service-oriented government. With the deepening of administrative system reform, the current Chinese socialistic legal system is improved constantly and the people have strong sense of democracy. As a result, it is necessary to implement administrative accountability comprehensively and thoroughly. Administrative accountability system is a modern administrative system, a mechanism to supervise government and civil servants, an important means of power control and accountability and an important means of government management.
\end{abstract}

Keywords-responsible government; administrative accountability system; right restriction

\section{CONNOTATION AND COMPONENTS OF ADMINISTRATIVE ACCOUNTABILITY SYSTEM}

\section{A. Connotation of Administrative Accountability System}

Administrative accountability system refers to the system for the government's internal supervision and accountability toward the leaders of the current government at the same level, main responsible persons of various government-owned departments and the government at lower level for their negligence and intentional act, nonperformance or improper fulfillment of their legal duties within the departments governed by them and their working scope, which have influenced the administrative order and administrative efficiency, delayed the administrative affairs, or damaged the legitimate interests of people serviced by the administration, as well as the behavior causing adverse effects and consequences to administrative organs.

\section{B. Components of Administrative Accountability System}

1) Subject of Accountability: At present, the subject of administrative accountability in China is the unity of consubstantiality and vibrant, namely, the form of

Scientific Research Project: Project of model School Of Marxism and excellent teaching and research team construction for humanities and social science research of Ministry of Education 2016: Research on teaching system described in the important speech series of General Secretary Xi Jinping

Project of young and middle-aged Marxist theorist cultivation plan in colleges and universities in Hubei Province (Project No.: 16ZD057).

Wenjie Yi, Ph.D. candidate. combining coessential accountability and vibrant accountability, which is an aggregation of multiple forms. Coessential accountability refers to the accountability of its own level within the internal administrative system, and its accountability ways include: order to make a public apology and circulate a notice of criticism, order to resign, to be demoted or dismissed etc; vibrant accountability refers to the subject beyond the administrative system, specifically includes people's Congress, judiciary authorities, various democratic parties, news media, the public and other external accountability, and its main accountability ways are: question, inquiry, dismissal, resignation of the cabinet. Coessential accountability can supervise and control the daily work better, while vibrant accountability is of more binding effect and credibility.

2) Object of Accountability: Its targets are the governments at all levels and their civil servants. The primary ones are the leader shouldering responsibility for leadership directly or indirectly, as well as the civil servants who have improperly performed their duties and obligations.

3) Scope of Administrative Accountability: Administrative accountability shall not only be responsible for abuse of power, but also for the administrative omission and administrative arbitrary conduct, the major security incidents as well as the wrong decisions made by administrative officials. And the accountability shall not be confined to a particular aspect of the field, but should also include more incidents of other fields, and it shall not only carry out responsibility investigation on illegal errors, but also shall blame the behavior with deficient ability and damaging the government image. With the deepening and improvement of the administrative accountability system, the scope of administrative accountability tends to be broader.

4) Procedures of Accountability: The operation of a system shall be performed as per appropriate procedures. There is also strict legal procedure for the implementation of administrative accountability. Generally speaking, specific procedures of administrative accountability include such stages as start, investigation, decision, inform and implementation. Only with the clear, operable and detailed regulations for various links of the accountability, can it be ensured to be implemented smoothly. 


\section{IMPORTANCE OF THE IMPLEMENTATION OF ADMINISTRATIVE ACCOUNTABILITY SYSTEM}

\section{A. It Is Key to Comprehensively Promote the Law-based Administration and the Establishment of Responsible Government}

The implementation of administrative accountability is the key to comprehensively promote administration by law. The system will restrict the exercise of executive power if it cannot be operated normally and reasonably, and the exercise of civil rights will not be guaranteed, the law-based administration is unlikely to be promoted in the true sense. Administrative accountability system is an important way to achieve the establishment of responsible government, and the essential requirements to strengthen the government's responsibility, to improve government management, and to establish the responsible government.

\section{B. It Is Conducive to Promoting the Process of Political} Civilization, the Formation of New Administrative Culture, and to Provide Administrative Cultural Support for the Responsible Government

Administrative accountability shows the advanced concepts of responsible administration and public responsibility. So we can regard administrative accountability system as a kind of administrative system, and we can also see it as a kind of administrative culture. The core of administrative culture is the value orientation of administration. One of the value orientations of Chinese administrative culture is to be highly responsible for the national interest, collective interests and personal interest. The deepening and improvement of administrative accountability system is of great significance for the enhancement of sense of responsibility and self-discipline of the administrative personnel, the regulation of individual behavior and the improvement of administrative staff's quality, etc., which can form a new kind of administrative culture, to provide good environment for normal operation of administrative power. As a result, the powerful support can be provided for the construction of responsible government in China from the perspective of ideology.

\section{It Is Beneficial to Standardize Administrative Activities, to Prevent the Abuse of Power, and to Create Good Social Order}

The state administrative activities are the behaviors of public properties, which shall take society as the service object, and the public interest as target. State administrative activities cannot be arbitrary or irresponsible. Responsible administration is the necessary meaning of responsible government. The development of administrative accountability system can enable the executive authorities and their civil servants to establish their own sense of responsibility, thus to regulate their own administrative activities.

\section{It Is the Necessary Requirement to Promote Scientific, Democratic and Efficient Management of the Government}

Full implementation of administrative accountability and the definition of liability subject can effectively restrain and reduce administrative omission and administrative arbitrary conduct, strengthen the officials' awareness, and urge them to regulate their behavior, so as to administrative efficiency and implementation capacity of the government.

\section{DEVELOPMENT TREND OF CHINA'S ADMINISTRATIVE ACCOUNTABILITY SYSTEM AND THE MAIN PROBLEMS}

\section{A. Developing History and Trends of China's Administrative Accountability System}

1) Develop from relying mainly on coessential accountability to vibrant accountability: The critical point of developmental transformation is the event of "SARS". Prior to this event, coessential accountability is adopted in most cases, and after it, vibrant accountability is adopted simultaneously. Therefore, its role and significance are significant, which has triggered the real implementation of vibrant accountability.

2) Transform from power accountability to system accountability: Prior to the event of "SARS" in China, the accountability is primarily targeted various major accidents with unapparent meaning. After "SARS", the introduction of several new regulations marked the beginning of system accountability.

3) Transform from relying mainly on the administrative responsibility and legal responsibility to focusing on political responsibility and moral responsibility: In the previous practice, the matters of accountability are limited to abuse of power, ultra vires and other acts, yet administrative omission is easily to be overlooked. Now, the range of accountability matters is expanded: transforming from "making mistakes" to "omission", which has refined the classification of wrong behavior responsibility, but also has really formulated the specific criteria of omission, providing basis for people to follow.

4) Transform from emergency accountability mechanism to long-acting accountability system: In the past, relevant leaders are hold accountable only in case of major security incidents, and mostly are to solve the problems after the incidents. However, at present, institutional periodic review is conducted, and related work is done in advance, to finally make administrative accountability a "system". Currently, administrative organizations at all levels start to implement the accountability supervision system in China, to follow up and supervise accountability situation and progress in a timely manner, and record the accountability results in the personal file as an important basis for the performance-related evaluation, which has changed the incomplete approach of accountability in the past.

\section{B. Main Problems Exist in Current Administrative Accountability System in China \\ 1) Lack of ideological understanding: Since ancient times, the traditional thinking of "official position" is deeply rooted in}


the society. Most officials still firmly hold the decayed and backward thoughts, such as officials are masters and the ordinary people are servants, the officials are noble and the ordinary people are menial. The masses of people do not dare to expose the officials' misconduct due to their "fear" of officials as there is no accountability responsibility mechanism. It can be seen that, actually there is no strong accountability atmosphere in the whole country, let along the problem whether or not the accountability culture is solid.

2) Relatively weak vibrant accountability: Coessential accountability if frequently used in China, while vibrant accountability cannot effectively play its real role due to the lack of specific and normative operating procedures and the scientific definition as well as unclear scope of powers. In practice, the subjects of China's administrative accountability are still mainly the higher authorities and supervision departments. But the NPC and CPPCC have not played their due roles, with insufficient public participation and effect, insufficient accountability efforts of the people's court, inadequate judicial accountability efforts, and the media accountability need to be strengthened urgently. As a result, they have played a limited role.

3) Narrow accountability range: In the specific administrative accountability in China, the responsibility investigation is usually made after the serious safety accidents. And the accountability system hasn't played effective role in administrative malpractice, administrative omission and other issues. Although some areas pay attention to the blame the major administrative decision-making mistakes, in general terms, currently, the various laws and regulations haven't defined administrative accountability clearly. Moreover, the administrative accountability system varies in different regions in the implementation process, and the scope of accountability is not the same. This will make the administrative acts of the same nature be performed differently in different regions, thus affecting the law-based administration, and hindering the development of accountability system.

4) Imperfect accountability procedures and mechanisms, and the legal construction is lagged behind with inefficiency: The legitimate and accountability procedures are to guarantee the implementation of administrative accountability system. In the specific practice in China, the accountability procedures are short of legal operability and not transparent, with insufficient interdependence with judicial accountability, political accountability and moral accountability and other mechanisms, affecting the efficiency of administrative accountability to a certain extent. Meanwhile, there is almost blank for the legal regulation of decision-making responsibilities. The definition of administrative decisionmaking responsibilities and administrative implementation responsibilities is unclear, leading to many moral administrations, illegal decision-making and other acts cannot be hold accountable accordingly.

5) Unclear responsibility of accountability objects: With unclear responsibility, it is hard to determine which level and which particular leader shall be hold accountable in the event of problems. There is no clear definition of leaders' individual responsibility and collective responsibility. And the responsibility within various departments and the internal department is unclear, for example, there is no clear definition between the Party and government, the chief and deputy, as well as direct responsible person and indirect responsible person with overlapping functions.

6) Focusing on afterwards accountability without prevention in advance or supervision during the process: In the practice in China, the responsible person is only hold accountable after some critical incidents, which is obviously ex post. It is hard to remedy after the accident without supervision on crisis in advance. The subjects of China's supervision system are extensive, including political parties, authorities, administrative organs, judicial supervision, citizen supervision and supervision by public opinion. Citizen supervision is lack of effective ways and forms, staying only at the spontaneous and decentralized state compared with the executive power of administrative organs as well as the judicial power of judicial authorities. As the "supervision subject of the organs of power", the NPC and its standing committee have no special organs to perform the power of supervision. With insufficient supervision and strength, the administrative accountability supervision mechanism is seriously restricted to play an effective role.

7) Non-transparent accountability with unfair results: The returning procedures and results of officials are only publicized internally without opening to the outside, which is contrary to the principles of democratic law-based government Unfair results of accountability also exist, such as: investigate moral responsibility yet waive the legal responsibility, investigate the administrative responsibility instead of criminal liability, and investigate administrative sanctions instead of economic recovery.

Overall, the administrative accountability system is not only about the construction of government itself, but the more important role of it lies in improving government's executive ability, credibility and the party's ruling ability taking it as an opportunity, to achieve the ultimate goal of building socialist democratic politics. The government's executive ability is closely related to the effective operation of administrative system, and it directly affects the effectiveness of public policy implementation as well as its relationship with the masses. It is also related to whether or not the policies of the Party and the State can be really implemented, and whether or not the "scientific governance, democratic governance, law-based governance" can be achieved.

\section{COUNTERMEASURES TO IMPROVE ADMINISTRATIVE ACCOUNTABILITY SYSTEM}

The effective operation of administrative accountability system requires a good system security and the environment. As for the problems exist in the current administrative accountability practice, we shall change our concepts first of all, make clear various behavioral responsibilities, what kind of responsibility to fulfill and or to assume and other key links, innovate the mechanisms to improve the system. Therefore, the general idea is to clarify the internal logic of various matters of administrative accountability, and to establish the 
scientific and systematic rules and norms based on looking for and discovering the law.

\section{A. Strengthen Publicity and Guidance of Accountability Mechanisms, Deepen Cultural Construction of Administrative Accountability System, and Cultivate Positive Administrative Accountability Culture}

The atmosphere of investigating any responsibility, punishing any negligence and being strict for accountability shall be formed in the whole society, to enhance the awareness of supervision on power. We shall take Deng Xiaoping Theory and the important thought of "Three Represents" as guidance, thoroughly implement the scientific concept of development, improve the administrative accountability system, and improve the credibility and executive ability of government. Promote the construction of service-oriented government, responsible government, law-based government and clean government. Administrative accountability culture is the soul of administrative accountability system, which shall be publicized from public opinion and education as well as other aspects, improve the initiative and enthusiasm of accountability subject, enabling more people and institutions to be involved in.

\section{B. Give Play to Vibrant Accountability Actively}

First of all, the NPC accountability manner shall be regulated in detail by law, to clarify its responsibilities, strengthen self-construction of the NPC personnel, and strengthen their sense of responsibility and mission. At the same time, the system platform for the citizens to be involved in supervision shall be constructed; appropriate accountability procedures shall be developed, to improve the citizens' awareness and political participation ability. Absorb social accountability extensively, use the mass media comprehensively and effectively to obtain effective accountability results. The intervention efforts of judicial authority's accountability shall also be strengthened. Finally, an organic system shall be formed by virtue of organic combination.

\section{Expand the Scope of Administrative Accountability, and Give Full Play to the Correctional Role of Accountability}

First, it is necessary to clearly define the scope of accountability, which requires regulating the definition and classification of administrative accountability by law. For example, divide the responsibility of the government into political responsibility, administrative responsibility, legal responsibility, moral responsibility; or, divide it into economic regulation responsibility, market supervision responsibility, social management responsibility and public service responsibility according to government functions; or divide it into decision-making responsibility, implementation responsibility, supervision accountability in accordance with the administrative procedures; or divide it into nonperformance of their statutory duties and incorrect performance of their statutory duties according to the status of civil servants to perform their duties; or divide into leadership responsibility and job responsibilities according to the position responsibility. At the same time, while modifying and supplementing relevant regulations, arrangements or provisions, the central and local party and government organs shall refer to the useful practices of other provinces and municipalities, so that the provisions relating to the range of administrative accountability matters tends to be widened and unified, and change the current condition that is bad for accountability due to legislation vacancy as a result of narrow regulation scope. For example: strengthen the inspection, supervision and examination of routine work; extend from investigating officials who "have made mistakes" to the "nonaction" officials; strengthen the accountability of "decisionmaking mistakes" and "misconduct".

\section{Improve Administrative Accountability Procedures and Relief System}

As we all know, rights will be in vain without corresponding legal protection. Therefore, the behavior of administrative accountability system shall be regulated, and guarantee legal interest of the accountability subject and object at the same time, and establish scientific and reasonable administrative accountability procedures. As for the ways and methods of accountability, transform the simple afterwards responsibility investigation and administrative sanctions to clarifying responsibilities in advance, process supervision and control, performance evaluation and accountability; as for the administrative accountability process, it shall approach to the direction of regulating the appropriate steps, improve various steps, in particular the legal relief system of administrative accountability, and grant the rights of argument, complaints and action to accountability object. The hearing system can also be introduced in to carry out administrative accountability strictly according to the legal basis and legal procedures, thus to guarantee the rights of those personnel to be hold accountable and the fairness and justice of accountability results.

\section{E. Clearly Define the Administrative Responsibilities}

Clear definition of administrative responsibilities is the basis for establishment of administrative accountability system. We shall speed up the transformation of government functions, and divide the duties and powers of government departments scientifically and reasonably, break down the tasks and targets, so that each task shall have relevant clear regulations. At the same time, it shall be implemented to various positions and specific executives, ensuring everyone to perform in accordance with the detailed the rules and regulations, and each task having a clear accountability system. For example, the responsibility and authority between the party and the government, the chief and deputy, collective and individual as well as government and its departments shall be made clear.

\section{F. Improve the Legal System, Strengthen the Consolidated Supervision Mechanism for Executive Power, and Form the Accountability by Concerted Effort}

To improve administrative legislation responsibility system, establish the unified administrative accountability law and make clear responsibility investigation for illegal situations, the administrative accountability law is required to be established toward the direction of scientific, regulatory and operable, and be finalized in national legislation form, so as to 
grant it with authority and guarantee its implementation by virtue of state coercive power. As for the specific regulation of law on administrative accountability, China shall make the unified standard for the series problems such as accountability subject, object, and procedures by the legal form, and improve the relief programs related to relevant complaints, so that the unified national legislation and unified law enforcement can be achieved. At the same time, the support system construction shall be further strengthened, to establish a scientific and effective performance appraisal system, strengthen supervision and accountability on judicial authority, innovate administrative supervision ways, and strengthen the combination of administrative supervision with other forms of supervision.

\section{G. Make the Government Transparent, and the Governmental Affairs Open}

We shall improve the government's system of open governmental affairs, implement the government power list system, ensure the government activities can be faithfully opened to the public, protect the citizens' right to know and news media's right to report freely, at the same time, the information about official's punishment and return shall be revealed and publicized in a timely manner, so as to obtain the public's trust. Thus, the accountability system can be ensured to be implemented smoothly and be supported by the public.

\section{REFERENCES}

[1] Tang Tiehan. Frontier Problems of Administrative System Reform [M]. National School of Administration Press, 2008.

[2] Han Zhaozhu. Responsible Government and Accountability System [J]. Chinese Public Administration, 2007 (2).

[3] Fu Siming, Wang Lei. Discussion on Administrative Accountability System Construction in China [J]. New Vision, 2010 (05).

[4] Zhang Xihong. Several Problems of Constructing Accountability System for Service-oriented Government [J]. Chinese Public Administration, 2011 (12).

[5] Hu Xiang, Shi Xue. Theory and Practice of Administrative Accountability $[\mathrm{J}]$. Studies on Mao Zedong and Deng Xiaoping Theories, 2012 (07).

[6] Tian Xiangbo. Strengthening Accountability is the Key to Responsible Government Construction[N] The Procuratorate Daily, 2012-11-13.

[7] Zhou Yayue. Comparative Study on Administrative Accountability [M]. China's Procuratorate Press, 2008 (06).

[8] Cao Xiangyang. How to Improve Administrative Accountability System [N]. Guanghua Times, 2010-09-24.

[9] Li Junpeng. Responsible Government and Government Responsibility System [M]. People's Publishing House, 2009 (05)

[10] Li De. Current Dilemma Faced by Chinese Administrative Accountability and Reasons and Countermeasures [J]. Journal of China Executive Leadership Academy Pudong, 2015 (5). 